\title{
TNF- $\alpha$ - Mediated-p38-Dependent Signaling Pathway Contributes to Myocyte Apoptosis in Rats Subjected to Surgical Trauma
}

\author{
Huaxing Wu ${ }^{a, b}$ Guonian Wang ${ }^{b}$ Shuai Lib Mingyue Zhang ${ }^{b}$ Hulun Lic Kun Wang ${ }^{b}$
}

aSchool of Life science and technology, Harbin Institute of Technology, Harbin, bepartment of Anesthesiology, The Cancer Hospital, Harbin Medical University, Heilongjiang, Harbin, 'Department of Neuralbiology, Harbin Medical University, Heilongjiang, Harbin, China

\section{Key Words}

Surgical trauma • Myocyte-apoptosis • TNF- $\alpha \cdot$ MAPKs

\begin{abstract}
Background: The accumulation of cytokines in the plasma after trauma can induce myocyte apoptosis. We aimed to identify which cytokine(s) present in the plasma responsible for myocyte apoptosis, and delineated the signal transduction mechanism in rats subjected to surgical trauma. Methods: Rats were randomized into two groups: control and trauma groups, which was divided into five subgroups: posttraumatic $0,3,6,12$, and $24 \mathrm{~h}$ subgroups. Cardiomyocytes isolated from traumatized rats were incubated with one of the factors for 12 h (normal plasma; Cytomix; TNF- $\alpha$; IL-1 $\beta$; IFN- $\gamma$; trauma plasma; anti-TNF- $\alpha$ antibody; SB203580). Myocyte apoptosis, cytokine levels, and MAPKs activation, as the primary experimental outcomes, were measured by TUNEL, flow cytometry, ELISA and Western blot, respectively. Results: Myocyte apoptosis was induced by surgical trauma during the early stage after trauma. Accompanying this change, plasma TNF- $\alpha, \mathrm{IL}-1 \beta$, and IFN- $\gamma$ levels were elevated in traumatized rats. Incubation of traumatized cardiomyocytes with cytomix or TNF- $\alpha$ alone induced myocyte apoptosis, and increased the activation of p38 and ERK1/2. Myocyte apoptosis and p38 activation were elevated in traumatized cardiomyocytes with trauma plasma, and these increases were partly abolished by anti-TNF- $\alpha$ antibody or SB203580. Conclusion: Our study demonstrated that there exists the TNF- $\alpha$-mediated-p38-dependent signaling pathway that contributed to posttraumatic myocyte apoptosis of rats undergoing surgical trauma.
\end{abstract}

G. Wang contributed equally and thus share first authorship

Kun Wang MD

KARGER 125
Department of Anesthesiology, The Cancer Hospital, Harbin Medical University, 6 Baojian Road, Nangang District, Heilongjiang, Harbin 150081 (China)

Tel. +86-0451-86298811, Fax +86-0451-86298811, E-Mail hydwangkun@sina.com 


\section{Introduction}

Recently clinical reports indicated that surgical trauma can induce delayed myocardial injury in the absence of direct cardiac injury [1]. Cardiac dysfunction was a key contributor to mortality in patients undergoing abdominal surgery $[2,3]$. Hence, identifying the mechanisms responsible for trauma-induced cardiac injury and searching for therapeutic strategies to prevent secondary organ injury after trauma is critical in reducing overall morbidity and mortality.

Apoptosis plays a critical role in tissue injury and organ dysfunction under a variety of pathological conditions. Previous study demonstrated myocyte apoptosis occurred in the myocardium of rats following thermal injury, and was mediated by factors in the plasma $[4,5]$. In the mechanical injury model, myocyte apoptosis was observed, and proapoptotic mediators that trigger myocyte apoptosis were present in the plasma rather than cardiomyocytes themselves [6,7]. These studies provided a clue that myocyte apoptosis was induced by thermal or mechanical injury, as the pathologic basis of posttraumatic myocardial injury, and was secondary to an increase of plasma cytokine after injury. However, it is unknown whether myocyte apoptosis can be triggered by surgical trauma, and nor has studied which cytokine(s) present in the plasma accounts for myocyte apoptosis in rats undergoing surgical trauma.

Recent studies on the molecular mechanisms mediating apoptosis have focused on the activation of mitogen-activated protein kinases (MAPKs) signaling pathway in vivo and vitro trauma models [8]. MAPKs fall into three main families: p38, c-Jun N-terminal kinase (JNK) and extracellular signal-regulated kinase 1/2 (ERK1/2). Studies suggested that p38 and JNK were involved in apoptotic signaling in several cell types, and ERK1/2 kinase has been shown to survive of the cells [9]. The unbalance between the "death" signal mediated by p38 and JNK, and the "survival" signal generated by ERK1/2 will lead to cell apoptosis. Recently, study reported that p38, JNK and ERK1/2 were rapidly and transiently phosphorylated after mechanical injury, which resulted in cell apoptosis [10]. However, functional roles of MAPKs in determining myocyte apoptosis in rats undergoing surgical trauma have not been fully elucidated.

Therefore, the purpose of this study was to identify which cytokine(s) present in the plasma accounts for myocyte apoptosis, and if so, to delineate the signal transduction mechanisms in rats undergoing surgical trauma.

\section{Materials and Methods}

\section{Animal studies}

Male Sprague-Dawley (SD) rats (200-220 g) supplied by the Animal Center of Vital River Laboratories (Beijing, China), were acclimated in controlled conditions $\left(12: 12 \mathrm{~h}\right.$ light/dark cycle, $23 \pm 0.5^{\circ} \mathrm{C}$, relative humidity 40\%-60\%) for one week. All experiments were approved by the committee of Harbin Medical University, and performed in accordance with the Guide for the Care and Use of Laboratory Animals of the United States National Institute of Health. All surgery and sacrifice were performed under sodium pentobarbital anesthesia, and all efforts were made to minimize suffering.

\section{Experimental design and trauma procedure}

Rats were randomized into two groups: control group $(\mathrm{n}=10)$, and trauma group $(\mathrm{n}=50)$, which was divided into five subgroups: posttraumatic 0 (immediately after trauma), 3, 6, 12, and 24 h subgroups ( $\mathrm{n}=10$ per subgroup) by using a computer-generated random number table. All rats were fasted overnight but allowed water ad libitum before the experiment. Traumatized rats were anesthetized with an intraperitoneal injection of pentobarbital sodium $(40 \mathrm{mg} / \mathrm{kg})$ at 9:00 AM. As described by Wang et al. [11], rats were aseptically incised longitudinally to a length of $6 \mathrm{~cm}$ along the dorsal median line and $5 \mathrm{~cm}$ along the abdominal median line, and the abdominal viscera were exposed for $3 \mathrm{~min}$. After ensuring there was no bleeding in the abdominal cavity, the wound was sutured and covered with adhesive dressing. The duration of surgery was 15-20 min. Rats were awaked 5-10 min after trauma, and provided with water and food ad libitum. Rats of control group were only anesthetized without surgical trauma. After completion of 


\section{Cellular Physiology Cell Physiol Biochem 2015;35:1454-1466 \begin{tabular}{ll|l} 
and: 10.1159/000373965 & $\begin{array}{l}\text { O 2015 S. Karger AG, Basel } \\
\text { www.karger.com/cpb }\end{array}$ \\
\hline
\end{tabular} \\ Wu et al.: Plasma TNF- $\alpha$ Mediated Myocyte Apoptosis}

the procedure, rats of control group were immediately killed, and traumatized rats allowed to recover in a warmed chamber and killed $0,3,6,12$, and $24 \mathrm{~h}$ after trauma.

Previous studies [12-14] and our experiment [15] demonstrated that the surgical trauma model of rats can imitate clinical features, and was used to illustrate the effects of surgical trauma and stress on the body function, and this model was relatively easy to perform. Surgical trauma and anesthesia were performed by two researchers who were not involved in data acquisition and analysis. Research assistants who collected the measurements and performed the assays were blinded to group assignments.

Cardiomyocytes culture and treatments

To examine trauma-induced myocyte aopotosis, hearts were collected at several times; Calciumtolerant adult rat ventricular myocytes (ARVMs) were isolated from hearts of control or traumatized rats as described by Singh [16]. Briefly, hearts were perfused retrogradely with nominally $\mathrm{Ca}^{2+}$-free Krebs-Henseleit bicarbonate buffer and were minced and dissociated in the same buffer containing $0.02 \mathrm{mg} / \mathrm{mL}$ trypsin and $0.02 \mathrm{mg} / \mathrm{mL}$ deoxyribonuclease (Sigma, St. Louis, MO). The cell mixture was filtered and sedimented through $60 \mu \mathrm{g} / \mathrm{mL}$ bovine serum (Sigma) albumin to separate ventricular myocytes from nonmyocyte cells.

The cell pellet was resuspended in ACCT medium consisting of Dulbecco's modified Eagle's medium with $2 \mathrm{mg} / \mathrm{mL}$ bovine serum albumin, $2 \mathrm{mM} \mathrm{L}$-carnitine, $5 \mathrm{mM}$ creatine, $5 \mathrm{mM}$ taurine, $100 \mathrm{IU} / \mathrm{mL}$ penicillin, and $100 \mu \mathrm{g} / \mathrm{mL}$ streptomycin (Sigma). The ARVMs were then plated at $0.5-1 \times 10^{4}$ cells $/ \mathrm{cm}^{2}$ in culture dishes (Thermo Fisher Scientific, Waltham, MA) precoated with laminin (1 $\mu \mathrm{g} / \mathrm{cm}^{2}$; BD Biosciences, San Jose, CA). After $1 \mathrm{~h}$, the dishes were washed with ACCT to remove the nonadherent cells. Experiments were performed following $16 \mathrm{~h}$ of culture at $37^{\circ} \mathrm{C}$ in a humidified atmosphere $\left(5 \% \mathrm{CO}_{2}\right.$ and $95 \%$ air).

To identify the specific cytokine(s) responsible for mediating myocyte apoptosis after surgical trauma, cardiomyocytes isolated from traumatized rats (traumatized cardiomyocytes) were incubated with one of the following factors for $12 \mathrm{~h}$ : normal plasma, trauma plasma (isolated $6 \mathrm{~h}$ after trauma), and Cytomix (a mixture of $10 \mathrm{ng} / \mathrm{mL}$ TNF- $\alpha, 1 \mathrm{ng} / \mathrm{mL}$ IL-1 $\beta$, and 1,000 U/mL IFN- $\gamma$; PeproTech Inc., New Jersey, USA) [17]; individual components of Cytomix at one to three times the concentration used in the mixture; or trauma plasma plus anti-TNF- $\alpha$ antibody ( $1 \mu \mathrm{g} / \mathrm{mL}$; Abcam Inc., Cambridge, UK) [18].

To delineate the role of p38, JNK1/2, and ERK1/2 in myocyte apoptosis initiated by surgical trauma, cardiomyocytes isolated from traumatized rats were subjected to one of the following treatments: normal plasma, trauma plasma, and trauma plasma plus SB203580 (a highly selective p38 inhibitor, $10 \mu$ M; Sigma) [10]. Each experimental condition listed above was examined in triplicate using cardiomyocytes isolated from the same animal. Results from the same animal were averaged and counted as one sample. At the end of the experiments, myocyte apoptosis and MAPKs activation were determined.

In situ detection of myocyte apoptosis in vivo by TUNEL assay

Heart tissue was fixed in $10 \%$ formalin, embedded in paraffin, and sectioned at $4 \mu \mathrm{m}$. The slides were processed for TUNEL assay by using the In Situ Cell Death Detection Kit (Roche, Indianapolis, IN). Briefly, the slides were treated with $20 \mu \mathrm{g} / \mathrm{mL}$ proteinase $\mathrm{K}$ and $\mathrm{H}_{2} \mathrm{O}_{2}$, and then incubated with the TUNEL reaction mixture containing TdT and fluorescein-dUTP for $1 \mathrm{~h}$ at $37^{\circ} \mathrm{C}$. Labeled DNA was visualized with peroxide as econjugated antifluorescein antibody using 3,3'-diaminobenzidine as the chromogen. After that, each slide was processed with hematoxylin to stain nonapoptotic cell nuclei. Sections pretreated with DNase I $(10 \mathrm{U} / \mathrm{mL})$ for $20 \mathrm{~min}$ at $37^{\circ} \mathrm{C}$ were used as positive controls and sections for which TdT was omitted from the reaction mixture were used as negative controls. Entire tissue sections from each myocardial specimen were examined and the numbers of TUNEL-positive cardiomyocytes and total cardiomyocytes were counted using a light microscope with an eyepiece grid (magnification $\times 200$ ); Cardiomyocyte apoptotic rates were calculated as the ratio of the numbers of TUNEL positive cardiomyocytes to the numbers of total cardiomyocytes. Results from different fields taken from the same animal were averaged and counted as one sample.

Flow cytometric analysis of isolated myocyte apoptosis

Cardiomyocytes were washed with PBS, centrifuged at $800 \mathrm{X} \mathrm{g}$ for $6 \mathrm{~min}$, resuspended in ice-cold $70 \%$ ethanol/PBS, centrifuged at $800 \mathrm{X} \mathrm{g}$ for a further $6 \mathrm{~min}$, and resuspended in PBS. Cells were then incubated with propidium iodide (PI) and FITC-labelled Annexin V (BD Biosciences) for 30 min at $37^{\circ} \mathrm{C}$. Excess PI and Annexin V were then washed off. Cells were fixed and then stained cells were analysed by flow cytometry using FACS Calibur (Becton Dickinson, Mountain View, CA) equipped with $488 \mathrm{~nm}$ argon laser 


\section{Cellular Physiology Cell Physiol Biochem 2015;35:1454-1466 \begin{tabular}{l|l} 
DOI: 10.1159/000373965 & $\begin{array}{l}\text { O 2015 S. Karger AG, Basel } \\
\text { www.karger.com/cpb }\end{array}$ \\
\hline
\end{tabular} \\ Wu et al.: Plasma TNF- $\alpha$ Mediated Myocyte Apoptosis}

light source; $515 \mathrm{~nm}$ band pass filter for FITC-fluorescence and $623 \mathrm{~nm}$ band pass filter for PI-fluorescence using CellQuest software. A dot plot of PI- fluorescence ( $\mathrm{y}$-axis) versus FITC-fluorescence (x-axis) has been prepared.

Colorimetric assays of cardiomyocytes caspase-3, 8, and 9 activities

The activity of caspases-3, 8, and 9 was measured with colorimetric assays using the caspase-3 (R\&D Systems, Love Molly weir, CA), caspase-8 (Chemicon International Inc., CA), and caspase- 9 (Calbiochem) assay kit. Briefly, cells were washed twice with ice-cold PBS and resuspended in cell lysis buffer. Cell lysates were centrifuged, and the supernatants were incubated with the colorimetric substrate Ac-Asp-Glu-ValAsp- $p$ - nitroanilide (Ac-DEVD- $p N A$ ), $N$-acetyl-Ile-Glu-Thr-Asp- $p$-nitroanilide (Ac-IETD- $p N A$ ), or Ac-Leu-GluHis- Asp- $p$-nitroanilide (Ac-LEHD- $p$ NA) for caspases-3, 8, and 9, respectively. The release of $p$ NA from AcDEVD- $p$ NA, Ac-IETD- $p$ NA, or Ac-LEHD- $p$ NA was measured at $405 \mathrm{~nm}$ using a spectrophotometer. Data were given as relative units (folds over NP).

\section{ELISA assays of plasma cytokines}

To determine the time course of plasma TNF- $\alpha$, IL- $1 \beta$, and IFN- $\gamma$ production after trauma, rats were sacrificed $0,3,6,12$ and $24 \mathrm{~h}$ after trauma. Blood samples were obtained and the concentrations of plasma TNF- $\alpha$, IL-1 $\beta$, and IFN- $\gamma$ were determined by use of double antibody Quantikine Enzyme-linked immunosorbent (ELISA) kits (Shanghai Senxiong Science and Technology Company, Shanghai, China).

Western blot analysis of cardiomyocytes MAPKs, Bax and Bcl-2

Briefly, the protein of each cell lysate was separated on $10 \%$ sodium dodecyl sulfatepolyacrylamide gel electrophoresis and electrotransferred to a polyvinylidene difluoride membrane (Bio-Rad Laboratories, Hercules, CA). The membranes were saturated with blocking buffer for $1 \mathrm{~h}$ at room temperature and incubated with the antibody to Bcl-2 and Bax (500ng/mL), total-p38 (1:500 dilution), phos-p38 (1:500 dilution), total-JNK (1:500 dilution), and phos-JNK (1:500 dilution), total-ERK1/2 (1:500 dilution), phosERK1/2 (1:500 dilution) or $\beta$-actin (1:1000 dilution) (Santa Cruz, Los Angeles, CA) at $4^{\circ} \mathrm{C}$ overnight. After the membranes were washed three times in $0.3 \%$ Tween 20 /phosphate buffered saline for 10 min, they were incubated with an IRDye800 conjugated secondary antibody (Biotrend Chemikalien GmbH, Germany) in blocking buffer. Western blotting experiments were repeated three times. $\beta$-actin was used as an internal control. Protein-antibody complexes conjugated with IRDye800 were visualized on the Odyssey Infrared Imaging System, and quantified with Odyssey v1.2 software (LI-COR Biosciences, Bad Homburg, Germany). The densitometric values were performed by using the ratios of the measured proteins to $\beta$-actin, and then these values were given as relative units (folds over NP).

\section{Data analysis and statistics}

Power analysis was based on our results of preliminary experiments comparing cytokines and cardiomyocyte apoptosis at $6 \mathrm{~h}$ after trauma in traumatized rats compared with control rats and yielded a sample size of $n=10(\alpha=0.05 ; 1-\beta=0.9)$ for per group or subgroup. Data were analyzed with SPSS 13.0 software (serial 5031432, Stats Data Mining Co., China). Western blot densities were analyzed with the Kruskal-Wallis test followed by Dunn post-hoc test. Other data were subjected to one way analysis of variance (ANOVA) followed by Bonferroni correction for post-hoc t test. $P<0.05$ was considered significant.

In the study, there was no adverse event in all experimental groups. Myocyte apoptosis and plasma TNF- $\alpha$, IL-1 $\beta$ and IFN- $\gamma$ levels in control group and trauma subgroups were measured $(n=10$ rats per group or subgroup). Cardiomyocyte caspases-3, 8, and 9 activities, expressions of Bax and Bcl-2, and MAPKs activation were measured by colorimetric assays and western blot analysis, respectively $(n=3$ independent experiments).

\section{Results}

Time course of myocyte apoptosis of traumatized rats

Myocyte apoptosis of the heart tissue in vivo was detected by in situ TUNEL staining. The TUNEL-positive cells had brown stained nuclei, which could be distinguished from the 


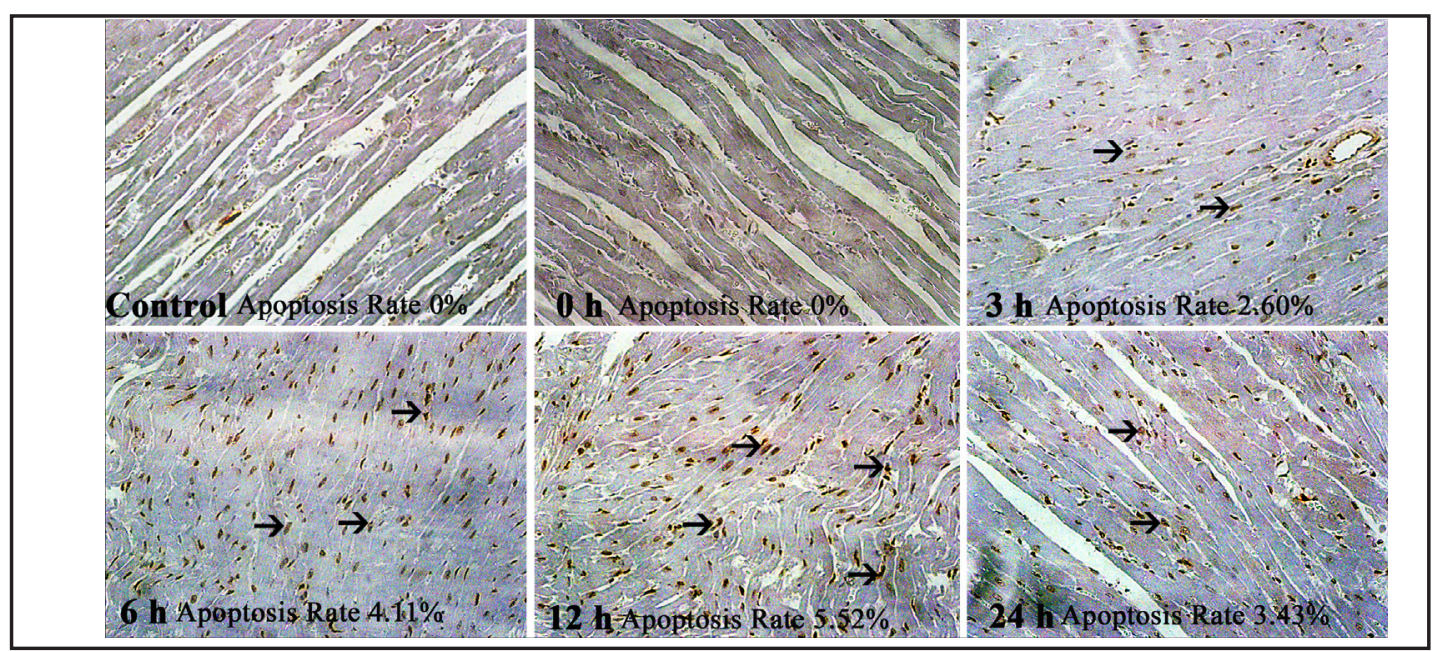

Fig. 1. Changes of myocyte apoptosis of the heart tissue after trauma. Pentobarbital anesthetized rats were subjected to control or trauma group. Trauma group included five subgroups: posttraumatic $0,3,6,12$, and $24 \mathrm{~h}$ subgroups. Their hearts were collected at several times, and myocyte apoptosis in the heart tissue was measured by situ DNA TUNEL staining. Representative figures showed myocyte apoptosis in control and traumatized rats. Arrows indicated the positive staining identifying apoptotic nuclei. Magnification $(\times 200)$. ${ }^{*} P<0.05$ vs. control. $\mathrm{n}=10$ rats per group or subgroup.

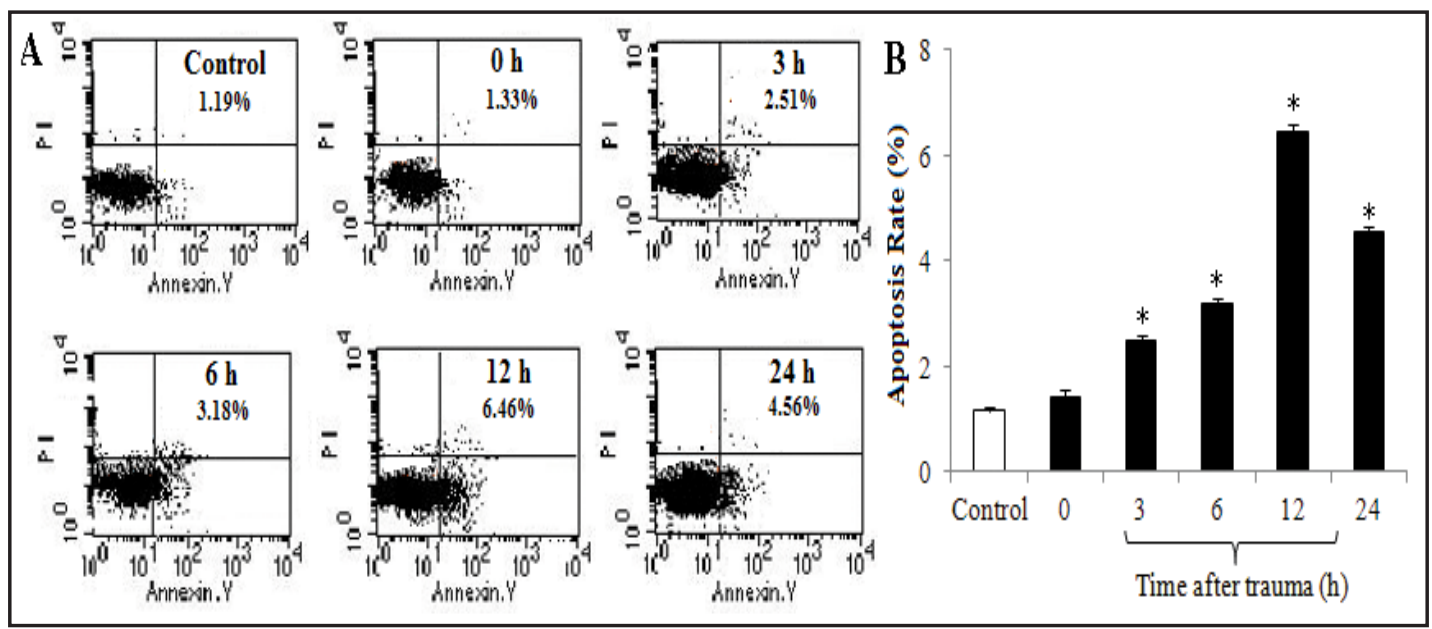

Fig. 2. Changes of isolated myocyte apoptosis after trauma. Pentobarbital anesthetized rats were subjected to control or trauma group. Trauma group included five subgroups: posttraumatic $0,3,6,12$, and $24 \mathrm{~h}$ subgroups. Their hearts were collected at several times, and isolated myocyte apoptosis was measured by Flow cytometry. ${ }^{*} P<0.05$ vs. control. $\mathrm{n}=10$ rats per group or subgroup.

blue stained nuclei of the nonapoptotic cells. No TUNEL-positive myocytes were detected in control rats and traumatized rats $0 \mathrm{~h}$ after trauma. As shown in Fig. 1, the TUNEL-positive cardiomyocytes were first observed $3 \mathrm{~h}$ after trauma, and the numbers showed further increases $6 \mathrm{~h}$ after trauma, and peaked $12 \mathrm{~h}$ after trauma, and thereafter decreased $24 \mathrm{~h}$ after trauma. The rate of myocyte apoptosis at $3,6,12$, and $24 \mathrm{~h}$ after trauma was $2.60 \%, 4.11 \%$, $5.52 \%$, and $3.43 \%$, respectively $(P<0.05$ vs control, Fig. 1$)$.

Isolated cardiomyocytes apoptosis from traumatized rats was measured by flow cytometry. Myocyte apoptosis was not observed in control rats and traumatized rats $0 \mathrm{~h}$ after trauma. The apoptosis rate increased $3 \mathrm{~h}$ after trauma $(2.51 \%)$, and reach a peak level $12 \mathrm{~h}$ after trauma (6.46\%), and then decreased gradually $24 \mathrm{~h}$ after trauma (4.56\%) $(P<0.05$ vs control, Fig. 2 A \& B). These results suggested that myocyte apoptosis was induced by surgical trauma.

\section{KARGER}


Fig. 3. Changes of plasma TNF- $\alpha$, IL- $1 \beta$ and IFN- $\gamma$ after trauma. Pentobarbital anesthetized rats were subjected to control or trauma group. Trauma group included five subgroups: posttraumatic $0,3,6,12$, and $24 \mathrm{~h}$ subgroups. Plasma samples were obtained at the specified time points, and TNF- $\alpha$ (A), IL-1 $\beta$ (B) and IFN- $\gamma(\mathrm{C})$ levels were measured by ELISA. ${ }^{*} P<0.05$ vs. control. $\mathrm{n}=10$ rats per group or subgroup.

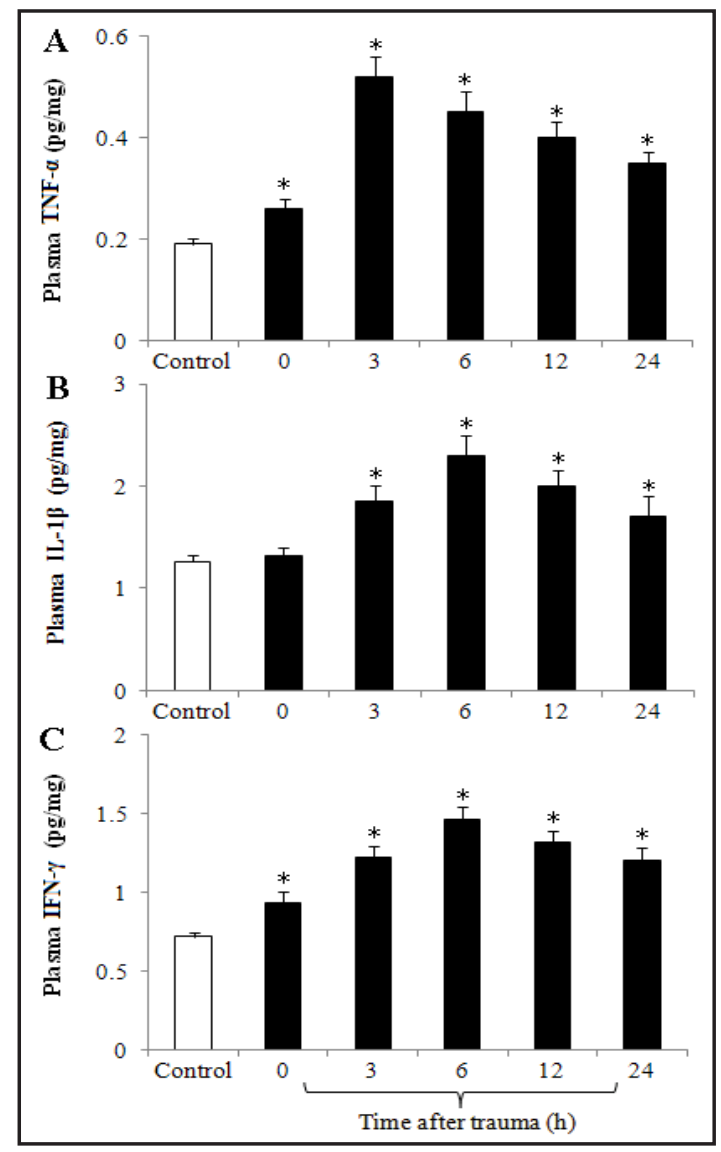

Time course of plasma cytokine levels in traumatized rats

At $0 \mathrm{~h}$ after trauma, plasma TNF- $\alpha$ level $(0.26 \mathrm{pg} / \mathrm{mg})$ was elevated in traumatized rats compared with control $(0.19 \mathrm{pg} / \mathrm{mg})(P<0.05)$. TNF- $\alpha$ level reached a peak level $3 \mathrm{~h}$ after trauma $(0.52 \mathrm{pg} / \mathrm{mg})$, then declined gradually thereafter (posttraumatic $6 \mathrm{~h}: 0.45 \mathrm{pg} / \mathrm{mg}, 12$ h: $0.40 \mathrm{pg} / \mathrm{mg}, 24 \mathrm{~h}: 0.35 \mathrm{pg} / \mathrm{mg})(P<0.05$ vs control, Fig. $3 \mathrm{~A})$.

At $0 \mathrm{~h}$ after trauma, plasma IL-1 $\beta$ level was not changed in traumatized rats. The increase of IL-1 $\beta$ was detectable $3 \mathrm{~h}$ after trauma $(1.85 \mathrm{pg} / \mathrm{mg})$, and reached a peak level 6 $\mathrm{h}$ after trauma $(2.30 \mathrm{pg} / \mathrm{mg})$, then decreased gradually (posttraumatic $12 \mathrm{~h}: 2.0 \mathrm{pg} / \mathrm{mg}, 24$ h:1.7 pg/mg) $(P<0.05$ vs control, Fig. 3B).

At $0 \mathrm{~h}$ after trauma, plasma IFN- $\gamma$ level $(0.93 \mathrm{pg} / \mathrm{mg})$ was elevated in traumatized rats, and increased gradually $3 \mathrm{~h}$ after trauma $(1.22 \mathrm{pg} / \mathrm{mg})$, and peaked $6 \mathrm{~h}$ after trauma $(1.46$ $\mathrm{pg} / \mathrm{mg}$ ), then declined thereafter (posttraumatic $12 \mathrm{h:} 1.32 \mathrm{pg} / \mathrm{mg}, 24 \mathrm{~h}: 1.2 \mathrm{pg} / \mathrm{mg})(P<0.05$ vs control, Fig. 3C).

These results suggested that levels of plasma TNF- $\alpha$, IL-1 $\beta$ and IFN- $\gamma$ were elevated in traumatized rats, although individual cytokines exhibited different time courses after trauma. Noticeably, all three cytokines peaked at or after $\sim 6 \mathrm{~h}$ after trauma, a time point that was about $6 \mathrm{~h}$ ahead of myocyte apoptosis occurring after trauma.

Identification of a specific cytokine responsible for myocyte apoptosis

As shown in Fig. 4A, the incubation of traumatized cardiomyocytes with normal plasma + Cytomix increased the activities of caspase-3, 8, and 9 compared with normal plasma $(P<0.01)$. The addition of IFN- $\gamma$ or IL-1 $\beta$ alone had no significant effect on caspase-3, 8 , and 9 activities. Addition of TNF- $\alpha$ alone at the concentration used in the Cytomix increased cardiomyocyte caspase- 3,8 , and 9 activities $(P<0.01$ vs normal plasma).

As shown in Fig. 4B, the incubation of traumatized cardiomyocytes with normal plasma + Cytomix increased the expression of the proapoptotic gene Bax, whereas that of antiapoptotic 
Fig. 4. Changes of the activities of caspases-3, 8 and 9, and the expression of Bax and Bcl-2 after the incubation of Cytomix, TNF- $\alpha$, IL- $1 \beta$ and IFN- $\gamma$. Cardiomyocytes isolated from traumatized rats (traumatized cardiomyocytes) were incubated with one of the following factors for $12 \mathrm{~h}$ : normal plasma; Cytomix (a mixture of 10 $\mathrm{ng} / \mathrm{mL}$ TNF- $\alpha, 1 \mathrm{ng} / \mathrm{mL}$ IL-1 $\beta$, and $1,000 \mathrm{U} / \mathrm{mL}$ IFN- $\gamma$ ); $10 \mathrm{ng} / \mathrm{mL}$ TNF- $\alpha$; $1 \mathrm{ng} / \mathrm{mL}$ IL-1 $\beta ; 1,000$ $\mathrm{U} / \mathrm{mL}$ IFN- $\gamma$. Caspases-3, 8, and 9 activities, and the expression of Bax and Bcl-2 were assayed by colorimetric assays and western blot, respectively. ${ }^{*} P<0.01$ vs. NP. $\mathrm{n}=3$ independent experiments.
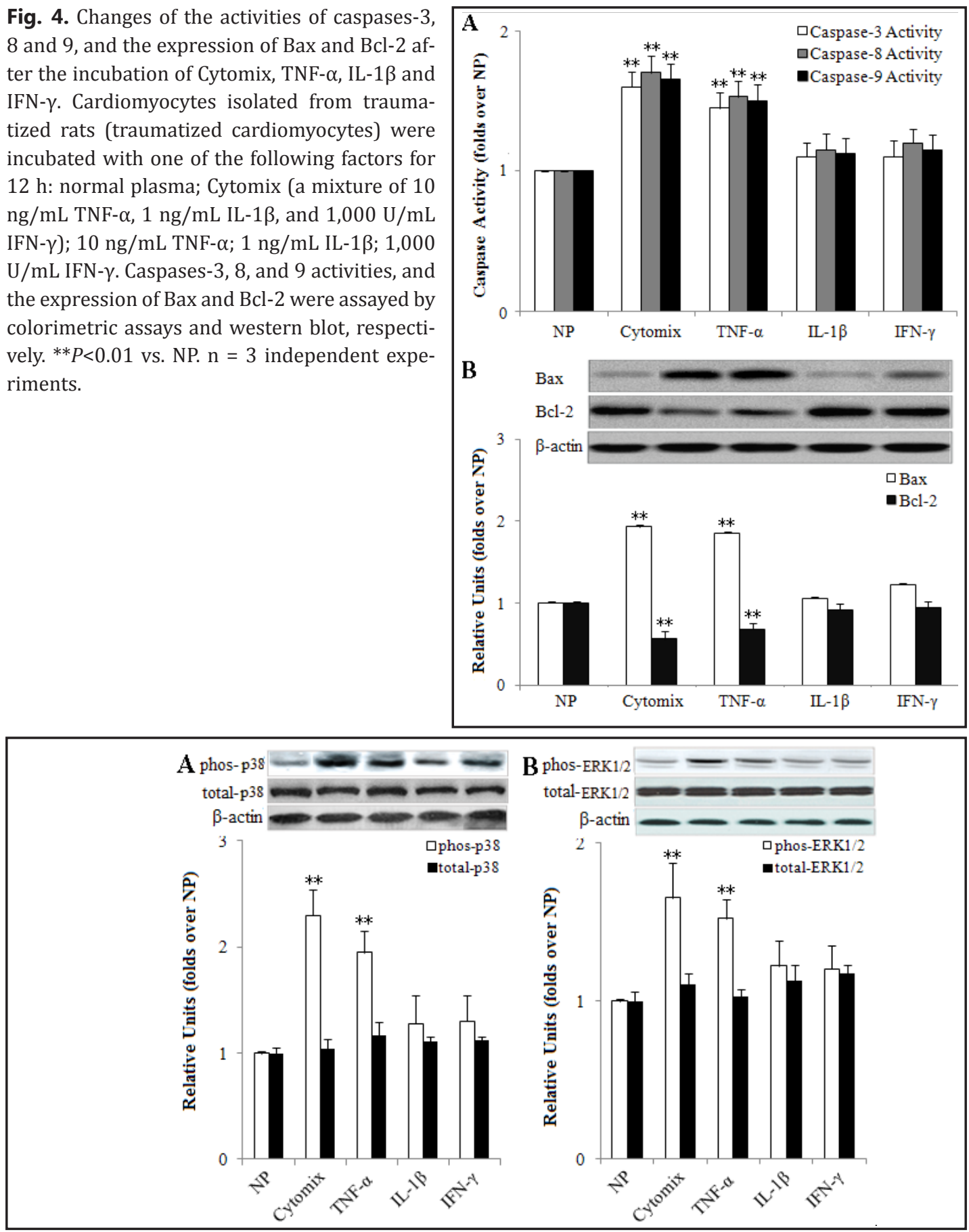

Fig. 5. Changes of MAPKs activation after the incubation of Cytomix, TNF- $\alpha$, IL-1 $\beta$ and IFN- $\gamma$. Cardiomyocytes isolated from traumatized rats (traumatized cardiomyocytes) were incubated with one of the following factors for $12 \mathrm{~h}$ : normal plasma (NP); Cytomix (a mixture of $10 \mathrm{ng} / \mathrm{mL}$ TNF- $\alpha, 1 \mathrm{ng} / \mathrm{mL}$ IL-1 $\beta$, and 1,000 U/ $\mathrm{mL}$ IFN- $\gamma$ ); $10 \mathrm{ng} / \mathrm{mL}$ TNF- $\alpha$; $1 \mathrm{ng} / \mathrm{mL}$ IL-1 $\beta$, and 1,000 U/mL IFN- $\gamma$. Total- and phos- of p38 and ERK1/2 were measured by western blot. ${ }^{*} P<0.01$ vs. NP. $\mathrm{n}=3$ independent experiments.

gene Bcl-2 was decreased compared with normal plasma $(P<0.01)$. The addition of IFN- $\gamma$ or IL-1 $\beta$ alone had no significant effect on the expression of Bax and Bcl-2. Addition of TNF- $\alpha$ alone at the concentration used in the Cytomix increased the expression of Bax, whereas that of Bcl- 2 was decreased ( $P<0.01$ vs normal plasma). 


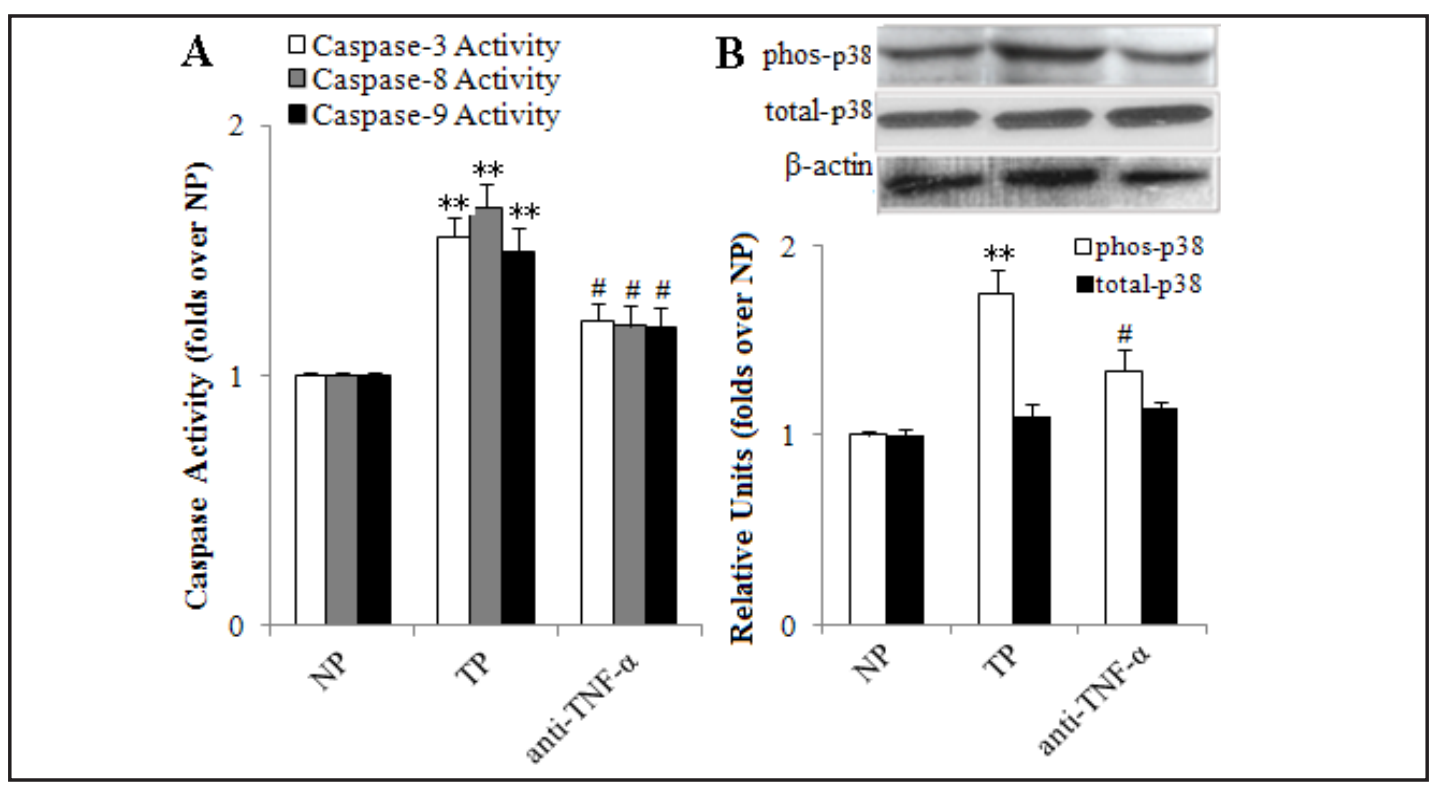

Fig. 6. Changes of caspases-3, 8, and 9 activities, and p38 activation after the incubation of anti-TNF- $\alpha$ antibody. Cardiomyocytes isolated from traumatized rats (traumatized cardiomyocytes) were incubated with one of the following factors for $12 \mathrm{~h}$ : normal plasma (NP); trauma plasma (TP); TP plus $1 \mu \mathrm{g} / \mathrm{mL}$ anti-TNF- $\alpha$ antibody. The activities of caspases-3, 8 and 9, and the expression of total- and phos-p38 were measured by colorimetric assays and western blot, respectively. ${ }^{* *} P<0.01$ vs. NP; ${ }^{*} P<0.05$ vs. TP. $\mathrm{n}=3$ independent experiments.

TNF- $\alpha$ linking myocyte apoptosis and MAPKs activation

As shown in Fig. 5A, the incubation of traumatized cardiomyocytes with normal plasma + Cytomix increased significantly p38 activation (phos-p38) compared with normal plasma $(P<0.01)$. The addition of IFN- $\gamma$ or IL-1 $\beta$ alone had no significant effect on p38 activation. However, the addition of TNF- $\alpha$ alone at the concentration used in the Cytomix increased p38 activation $(P<0.01$ vs normal plasma). There were no alterations of total-p38 among groups.

As shown in Fig. 5B, the incubation of traumatized cardiomyocytes with normal plasma + Cytomix increased ERK1/2 activation (phos-ERK1/2) compared with normal plasma $(P<0.01)$. No significant effect on ERK1/2 activation was observed when the addition of IFN- $\gamma$ or IL-1 $\beta$ alone. However, the addition of TNF- $\alpha$ alone at the concentration used in the Cytomix elevated ERK1/2 activation $(P<0.01$ vs normal plasma). There were no the significant changes of total-ERK1/2 among groups.

Both total- and phos-JNK were not altered among groups (not shown in the figures).

Compared with normal plasma, the activities of caspase-3, 8, and 9 was increased in traumatized cardiomyocytes with trauma plasma $(P<0.01$, Fig. $6 \mathrm{~A})$. Compared with trauma plasma, caspase-3, 8, and 9 activities were partly inhibited $(0.77,0.71$, and 0.78 folds, respectively) by anti-TNF- $\alpha$ antibody $(P<0.05)$. These results suggested that plasma antiTNF- $\alpha$ antibody decreased myocyte apoptosis of rats undergoing surgical trauma.

Compared with normal plasma, p38 activation (phos-p38) was increased 1.75 fold in traumatized myocytes with trauma plasma $(P<0.01$, Fig. 6B). Compared with trauma plasma, p38 activation was decreased 0.77 folds by anti-TNF- $\alpha$ antibody $(P<0.05)$. There were no significant changes of total-p38. Both total- and phos-ERK1/2 were not altered among groups (not shown in the figures). These results suggested that plasma TNF- $\alpha$ was responsible for posttraumatic myocyte apoptosis and p38 activation in rats undergoing surgical trauma.

\section{P38 involving TNF- $\alpha$-induced myocyte apoptosis}

Compared with normal plasma, caspase-3, 8, and 9 activities were increased in traumatized cardiomyocytes with trauma plasma $(P<0.01$, Fig. 7A). Compared with trauma 


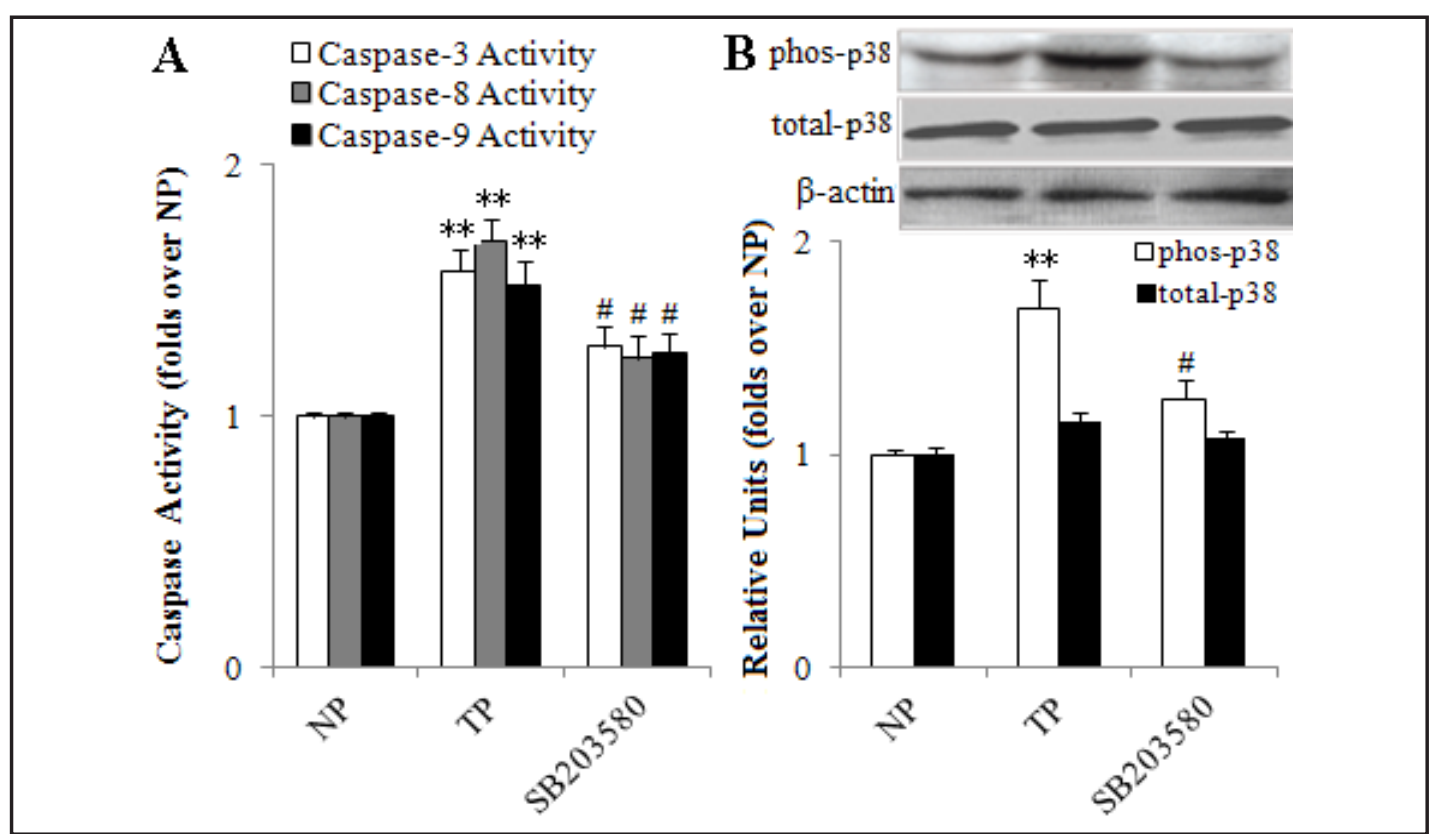

Fig. 7. Changes of caspases-3, 8, and 9 activities, and p38 activation after the incubation of SB203580. Cardiomyocytes isolated from traumatized rats (traumatized cardiomyocytes) were subjected to one of the following treatments for $12 \mathrm{~h}$ : normal plasma (NP); trauma plasma (TP); TP plus $10 \mu \mathrm{M} \mathrm{SB203580.} \mathrm{The} \mathrm{activities}$ of caspases-3, 8 and 9, and the expression of total- and phos-p38 were assayed by colorimetric assays and western blot, respectively. ${ }^{* *} P<0.01$ vs. NP; ${ }^{\#} P<0.05$ vs. TP. $\mathrm{n}=3$ independent experiments.

plasma, the activities of caspase- 3,8 , and 9 were inhibited partly $(0.81,0.73$, and 0.82 folds, respectively) by SB203580 $(P<0.05)$.

Compared with normal plasma, p38 activation (phos-p38) was increased 1.69 fold in traumatized cardiomyocytes with trauma plasma $(P<0.01$, Fig. 7B). Compared with trauma plasma, p38 activation was decreased 0.74 fold by SB203580 $(P<0.05)$. These results suggested that 38 pathway was involving in the TNF- $\alpha$-induced myocyte apoptosis in rats undergoing surgical trauma.

\section{Discussion}

Previous studies showed that myocyte apoptosis was observed during the early stage after sever burn or mechanical injury, which may account for posttraumatic cardiac dysfunction and even multiple organ dysfunction syndrome [4-7]. Recent studies have indicated a crucial role of the increased inflammatory cytokines in the plasma, such as TNF- $\alpha$, IL-1 $\beta$, and IFN- $\gamma$, and the importance of the subsequent activation of MAPKs in the induction of posttraumatic apoptosis [4-8]. Although myocyte apoptosis appeared in the several types of injury, to our study, no study has shown that myocyte apoptosis can be triggered by surgical trauma, and that trauma-induced apoptosis was causally linked to the plasma specific cytokine(s) and related MAPKs in the surgical trauma model of rats. In the present study, we had several novel observations. First, surgical trauma induced myocyte apoptosis of rats. Second, plasma TNF- $\alpha$ may contribute to posttraumatic myocyte apoptosis in rats undergoing surgical trauma. Finally, p38 activation was involving in the TNF- $\alpha$-mediated myocyte apoptosis. Taken together, our present study demonstrated that there existed a TNF$\alpha$-mediated-p38-dependent pathway that contributed to posttraumatic myocyte apoptosis in rats undergoing surgical trauma.

In this study, myocyte apoptosis appeared as early as posttraumatic $3 \mathrm{~h}$ and reached a peak level $12 \mathrm{~h}$ after trauma, and were still observed $24 \mathrm{~h}$ after trauma. The time course of 
myocyte apoptosis in our study was consistent with findings that myocyte apoptosis reached a maximal level $12 \mathrm{~h}$ after injury and remained a significantly high level $24 \mathrm{~h}$ after injury in the mechanical injury model [6]. This indicated that myocyte apoptosis appeared during the early period after trauma. In our study, we did not investigate the relation of myocyte apoptosis and posttraumatic cardiac dysfunction. To be clinically useful, therefore, additional studies required to further elucidate the changes of posttraumatic cardiac dysfunction.

Cytokines, such as TNF- $\alpha$, IL- $1 \beta$, and IFN- $\gamma$, are critical pro-apoptosis factors that cause cell death and tissue injury under various pathologic conditions [19]. It has been demonstrated that TNF- $\alpha$, IL- $1 \beta$, and IFN- $\gamma$ induced myocytes apoptosis in sever burn model [20]. Previous study showed that plasma TNF- $\alpha$ concentration was increased by mechanical injury (starting $1.5 \mathrm{~h}$ and peaking $12 \mathrm{~h}$ after injury), and mechanical injury induced TNF- $\alpha$ overproduction was the primary cause for myocyte apoptosis in traumatized rats [19]. In our study, myocyte apoptosis was observed in traumatized rats, and this was accompanied by an increase of plasma TNF- $\alpha$, IL- $1 \beta$, and IFN- $\gamma$. This result signified that the apoptotic phenomena were related to the accumulation of plasma TNF- $\alpha$, IL- $1 \beta$, and IFN- $\gamma$. Furthermore, all three cytokines peaked at or before posttraumatic $6 \mathrm{~h}$, a time point that was $6 \mathrm{~h}$ ahead of significant myocyte apoptosis occurring after trauma. These results strongly suggested that surgical trauma may result in the accumulation of inflammatory cytokines in the plasma, and then increased cytokines mediated posttraumatic myocyte apoptosis.

To further identify the specific cytokine(s) responsible for the induction of myocyte apoptosis, two additional experiments in vitro were performed. In the first series of experiments, traumatized cardiomyocytes were incubated with cytomix (a mixture of IFN- $\gamma$, IL-1 $\beta$, and TNF- $\alpha$ ) or alone, and the activities of caspases-3, 8 and 9, and the protein expression of Bax and Bcl-2 were determined. Executioner caspases are central to the apoptotic cascade because they mediate both the mitochondrial and the death receptor apoptotic pathways. Caspase-3, 8, and 9 are thought to be important in cardiomyocyte apoptosis [21]. Bcl-2 protein is a cytosolic protein with a lipid-anchoring domain which allows it to target the nucleus and to inhibit apoptosis. Bax, a member of the Bcl-family, homodimerizes and forms heterodimers with $\mathrm{Bcl}-2$ protein, reducing its anti-apoptotic effect. Bcl-2 and Bax have the opposite effects on the process of cell apoptosis. Previous study showed that Bcl-2 expression was markedly reduced in cardiac tissues by apoptosis-inducing stresses, whereas overexpression of Bax accelerated apoptotic death [22]. Our results showed that caspase-3, 8 , and 9 activities were increased, and the expression of Bax was up-regulated, and Bcl-2 was down-regulated after the incubation of traumatized cardiomyocytes with normal plasma + Cytomix/TNF- $\alpha$. It was consistent with above report, suggesting that altered expression of these apoptosis-related genes may be responsible for myocyte apoptosis. In the first series of experiments, our results demonstrated that although the addition of cytomix induced significant myocyte apoptosis, only TNF- $\alpha$ alone can induce myocyte apoptosis. In the second series of experiments, anti-TNF- $\alpha$ antibody was added into trauma plasma, and down-regulated the increase of myocyte apoptosis. In our study, we found that (1) the upregulation of TNF- $\alpha$ (at posttraumatic $3 \mathrm{~h}$ ) preceded the increase of IL-1 $\beta$ (at posttraumatic $6 \mathrm{~h}$ ), and was more than the increase of IFN- $\gamma$, suggesting a more potential role for TNF- $\alpha$ in the induction of apoptosis; (2) only TNF- $\alpha$ alone induced significant myocyte apoptosis, and the addition of anti-TNF- $\alpha$ antibody inhibited partly myocyte apoptosis. Collectively, these findings suggest that TNF- $\alpha$ was more likely to mediate myocyte apoptosis of rats undergoing surgical trauma. This was supported by recent finding that circulating TNF- $\alpha$ was the primary factor that mediated in vivo myocyte apoptosis in traumatized rats [19, $23,24]$. Although the exact explanation of surgical trauma induced TNF- $\alpha$ release was not studied in our experiments, the possibility can be explained that surgical trauma stimulated rapidly increased generation of reactive oxygen species (ROS) and NF-KB activation, which was associated with rapid increase of plasma TNF- $\alpha$ [25].

To characterize the signal transduction mechanism of TNF- $\alpha$-induced apoptosis, we examined the involvement of MAPKs pathway. Previous report disclosed that TNF- $\alpha$ activated various signaling pathways, such as p38, JNK and ERK1/2 [26]. TNF- $\alpha$ activated p38 and 
JNK, and then transduced a death signal via TNF receptor 1 (TNFR1)-TNFR-associated death domain (TRADD)-receptor interacting protein (RIP)-TNF receptor associated factor 2 (TRAF2) complexes [27]. P38 participated in the apoptosis generation by regulating the activation of caspase cascade pathway, and JNK can also lead to apoptosis by transcriptionallydependent (i.e., activation of the transcription factor AP-1) and transcription-independent (i.e., phosphorylation and activation of proapototic Bcl-2 proteins Bim and Bmf) mechanisms $[27,28]$. In addition to the activation of p38 and JNK, TNF- $\alpha$ also activated ERK, and then regulated cell proliferation and survival via the TNF receptor-associated factor 1 (TRAF1)Raf1-receptor interacting protein 2 (RIP2) cascade [29]. Persistent activation of p38 or JNK has been suggested to mediate apoptosis, whereas activation of ERK1/2 has been shown to inhibit apoptosis. Thus, whether the cell chose a survival or a death pathway depended on the interaction of various signaling pathways [30]. In our study, the incubation of traumatized cardiomyocytes with TNF- $\alpha$ induced myocyte apoptosis and the activation of p38 and ERK1/2. The incubation of traumatized cardiomyocytes with anti-TNF- $\alpha$ or SB203580 (a selective p38 inhibitor) attenuated myocyte apoptosis and p38 activation. These results demonstrated that p38 pathway was the primary signaling mechanism by which plasma TNF- $\alpha$-induced posttraumatic myocyte apoptosis. Recently, study has reported that the proinflammatory cytokines TNF- $\alpha$ can sensitize the kinase activity of ASK1, a reactive oxygen species-sensitive mitogen-activated protein kinase kinase kinase, and then ASK1 activated p38 kinase pathways [31]. Once activated, p38 phosphorylates a variety of intracellular targets, including transcription factors and protein kinases, and these targets may promote apoptosis [32]. P38 can also sensitize cells to apoptosis through the positive regulation of Fas/CD-95 and Bax expression [33], and Bcl-XL deamidation [34]. Aboved reports further supported our results that p38 pathway played the important role in the induction of apoptosis. Besides pro-apoptotic function, anti-apoptotic action has been ascribed to p38 [35]. Whether p38 acts as a cytoprotective or pro-apoptotic agent likely depends on both the intensity and duration of $\mathrm{p} 38$ activation. In the present study, our results showed that TNF- $\alpha$ activated p38 pathway, and the subsequent activation of p38 mediated myocyte apoptosis. It was consistent with previous report that myocyte susceptibility to apoptosis was potentiated when p38 activation was prolonged by tyrosine phosphatase inhibition [35].

In our study, the results were appeared the similar change trend between the incubation of anti-TNF- $\alpha$ antibody and the incubation of SB203580, which might be related to the selection of the concentration and dose of two antibodies. The role of JNK and ERK1/2 pathways was somewhat controversial. It may be owing to that the roles of JNK and ERK1/2 in mediating apoptosis may be highly dependent on the types of the stimuli and cells [36]. Further investigation will be required to determine how the pathways (p38, JNK and ERK1/2) interact.

In conclusions, present study demonstrated that myocyte apoptosis was mediated by plasma TNF- $\alpha$ via p38 signaling pathway in rats undergoing surgical trauma, suggesting that there exists a TNF- $\alpha$-mediated-p38- dependent signaling pathway that contributed to posttraumatic myocyte apoptosis. This study sheds new light on the pathologic basis of trauma induced myocardial injury, and those therapeutic interventions blocking TNF- $\alpha$ or p38 pathway may attenuate the secondary organ injury after trauma.

\section{Disclosure Statement}

The authors declare that they have no conflict of interest.

\section{Acknowledgements}

We are grateful to Dr. Jialan Shi (Department of Medicine, Brigham and Women's Hospital and Harvard Medical School) for help in preparing the manuscript. The study was funded by the Provincial Health Department of Heilongjiang, Heilongjiang Postdoctoral 


\begin{tabular}{|c|c|c|}
\hline Cellular Physiology & Cell Physiol Biochem 2015;35:1454-1466 & \\
\hline and Biochemistr & $\begin{array}{l}\text { DOI: 10.1159/0003739665 } \\
\text { Published online: March 12, } 2015\end{array}$ & $\begin{array}{l}\text { O } 2015 \text { S. Karger AG, Basel } \\
\text { www.karger.com/cpb }\end{array}$ \\
\hline
\end{tabular}

Fund (No. LBH-Z12187), China Postdoctoral Science fund (No. 2013M531070), National Nature Science Fund of China (81401584) and Medicine Research Fund of the Third Clinical Hospital of Harbin Medical University (No. JJZ2011-05). The funders had no role in study design, data collection and analysis, decision to publish, or preparation of the manuscript.

\section{References}

1 Wang J, Lu K, Liang F, Li X, Wang L, Yang C, Yan Z, Zhang S, Liu H: Decreased autophagy contributes to myocardial dysfunction in rats subjected to nonlethal mechanical trauma. PLoS One 2013;8:e71400.

2 Choi JH, Cho DK, Song YB, Hahn JY, Choi S, Gwon HC, Kim DK, Lee SH, Oh JK, Jeon ES: Preoperative NT-proBNP and CRP predict perioperative major cardiovascular events in non-cardiac surgery. Heart 2010;96:56-62.

3 Kim GS, Ahn HJ, Kim WH, Kim MJ, Lee SH: Risk factors for postoperative complications after open infrarenal abdominal aortic aneurysm repair in Koreans. Yonsei Med J 2011;52:339-346.

4 Horton JW: Cellular basis for burn-mediated cardiac dysfunction in adult rabbits. Am J Physiol 1996;271:H2615-H2621.

5 Carlson DL, Lightfoot E Jr, Bryant DD, Haudek SB, Maass D, Horton J, Giroir BP: Burn plasma mediates cardiac myocyte apoptosis via endotoxin. Am J Physiol Heart Circ Physiol 2002;282:H1907-H1914.

6 Tao L, Liu HR, Gao F, Qu Y, Christopher TA, Lopez BL, Ma XL: Mechanical traumatic injury without circulatory shock causes cardiomyocyte apoptosis: role of reactive nitrogen and reactive oxygen species. Am J Physiol Heart Circ Physiol 2005;288:H2811-H2818.

7 Li S, Jiao X, Tao L, Liu H, Cao Y, Lopez BL, Christopher TA, Ma XL: Tumor necrosis factor-alpha in mechanic trauma plasma mediates cardiomyocyte apoptosis. Am J Physiol Heart Circ Physiol 2007;293:H1847-H1852.

8 Oh CC, Nguy MQ Schwenke DC, Migrino RQ Thornburg K, Reaven P: p38 $\alpha$ mitogen-activated kinase mediates cardiomyocyte apoptosis induced by palmitate. Biochem Biophys Res Commun 2014;450:628633.

9 Kikuchi M, Tenneti L, Lipton SA: Role of p38 mitogen-activated protein kinase in axotomy-induced apoptosis of rat retinal ganglion cells. J Neurosci 2000;20:5037-5044.

10 Serbest G, Horwitz J, Jost M, Barbee K: Mechanisms of cell death and neuroprotection by poloxamer 188 after mechanical trauma. FASEB J2006;20:308-310.

11 Wang J, Wang YQ, Yu J, Cao XD, Wu GC: Electroacupuncture suppresses surgical trauma stress-induced lymphocyte apoptosis in rats. Neurosci Lett 2005;383:68-72.

12 Cheng XD, Wu GC, Jiang JW, Du LN, Cao XD: Dynamic observation on regulation of electroacupuncture on the proliferation responses of spleen lymphocytes from traumatized rats. Chin J Immunol 1997;13:68-70.

13 Cao XD: Involvement of orphanin FQ in electroacupuncture modulation on immunosuppression by trauma. Zhen Ci Yan Jiu 2001;26:219-220

14 Cheng XD, Wu GC, He QZ, Cao XD: Effect of continued electroacupuncture on induction of interleukin-2 production of spleen lymphocytes from the injured rats. Acupunct Electrother Res 1997;22:1-8.

15 Wang K, Wu H, Wang G, Li M, Zhang Z, Gu G: The effects of electroacupuncture on TH1/TH2 cytokine mRNA expression and mitogen-activated protein kinase signaling pathways in the splenic $\mathrm{T}$ cells of traumatized rats. Anesth Analg 2009;109:1666-1673.

16 Communal C, Colucci WS, Singh K: p38 mitogen-activated protein kinase pathway protects adult rat ventricular myocytes against beta-adrenergic receptor-stimulated apoptosis. Evidence for Gi-dependent activation. J Biol Chem 2000;275:19395-19400.

17 Potoka DA, Nadler EP, Zhou X, Zhang XR, Upperman JS, Ford HR: Inhibition of NF-kappaB by IkappaB prevents cytokine-induced NO production and promotes enterocyte apoptosis in vitro. Shock 2000;14:366373.

18 Kadokami T, Frye C, Lemster B, Wagner CL, Feldman AM, McTiernan CF: Anti-tumor necrosis factor-alpha antibody limits heart failure in a transgenic model. Circulation 2001;104:1094-1097.

19 Keel M, Trentz O: Pathophysiology of polytrauma. Injury 2005;36:691-709.

20 Zhang JP, Ying X, Liang WY, Luo ZH, Yang ZC, Huang YS, Wang WC: Apoptosis in cardiac myocytes during the early stage after severe burn. J Trauma 2008;65:401-408. 


\section{Cellular Physiology Cell Physiol Biochem 2015;35:1454-1466

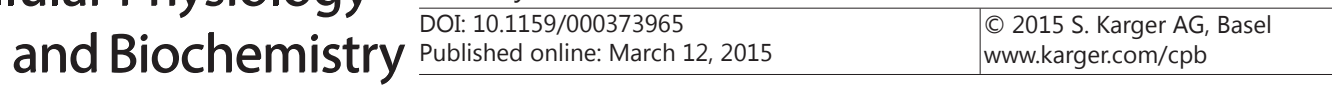 \\ Wu et al.: Plasma TNF- $\alpha$ Mediated Myocyte Apoptosis}

21 Cook SA, Poole-Wilson PA: Cardiac myocyte apoptosis. Eur Heart J 1999;20:1619-1629.

22 Xie Z, Koyama T, Suzuki J, Fujii Y, Togashi H, Sawa H, Nagashima K: Coronary reperfusion following ischemia: different expression of bcl-2 and bax proteins, and cardiomyocyte apoptosis. Jpn Heart J 2001;42:759-770.

23 Li S, Tao L, Jiao X, Liu H, Cao Y, Lopez B, Luan RH, Christopher T, Ma XL: TNF alpha-initiated oxidative/ nitrative stress mediates cardiomyocyte apoptosis in traumatic animals. Apoptosis 2007;12:1795-1802.

24 Feuerstein GZ, Young PR: Apoptosis in cardiac diseases: stress- and mitogen-activated signaling pathways. Cardiovasc Res 2000;45:560-569.

25 Nitobe J, Yamaguchi S, Okuyama M, Nozaki N, Sata M, Miyamoto T, Takeishi Y, Kubota I, Tomoike H: Reactive oxygen species regulate FLICE inhibitory protein (FLIP) and susceptibility to Fas-mediated apoptosis in cardiac myocytes. Cardiovasc Res 2003;57:119-128.

26 Kanaji N, Nelson A, Wang X, Sato T, Nakanishi M, Gunji Y, Basma H, Michalski J, Farid M, Rennard SI, Liu X: Differential roles of JNK, ERK1/2, and p38 mitogen-activated protein kinases on endothelial cell tissue repair functions in response to tumor necrosis factor- $\alpha$. J Vasc Res 2013;50:145-156.

27 Wallach D, Varfolomeev EE, Malinin NL, Goltsev YV, Kovalenko AV, Boldin MP: Tumor necrosis factor receptor and Fas signaling mechanisms. Annu Rev Immunol 1999;17:331-367.

28 Guicciardi ME, Gores GJ: AIP1: a new player in TNF signaling. J Clin Invest 2003;111:1813-1815.

29 Navas TA, Baldwin DT, Stewart TA: RIP2 is a Raf1-activated mitogen-activated protein kinase kinase. J Biol Chem 1999;274:33684-33690.

30 Gill C, Mestril R, Samali A: Losing heart: the role of apoptosis in heart disease-a novel therapeutic target? FASEB J 2002;16:135-146.

31 Nishida K, Otsu K: The role of apoptosis signal-regulating kinase 1 in cardiomyocyte apoptosis. Antioxid Redox Signal 2006;8:1729-1736.

32 Roux PP, Blenis J: ERK and p38 MAPK-activated protein kinases: a family of protein kinases with diverse biological functions. Microbiol Mol Biol Rev 2004;68:320-344.

33 Porras A, Zuluaga S, Black E, Valladares A, Alvarez AM, Ambrosino C, Benito M, Nebreda AR: P38 alpha mitogen-activated protein kinase sensitizes cells to apoptosis induced by different stimuli. Mol Biol Cell 2004;15:922-933.

34 Ren J, Zhang S, Kovacs A, Wang Y, Muslin AJ: Role of p38alpha MAPK in cardiac apoptosis and remodeling after myocardial infarction. J Mol Cell Cardiol 2005;38:617-623.

35 Andreka P, Nadhazi Z, Muzes G, Szantho G, Vandor L, Konya L, Turner MS, Tulassay Z, Bishopric NH: Possible therapeutic targets in cardiac myocyte apoptosis. Curr Pharm Des 2004;10:2445-2461.

36 Liu ZG: Adding facets to TNF signaling. The JNK angle. Mol Cell 2003;12:795-796. 